\title{
Kinematic analysis of males with transtibial amputation carrying military loads
}

\author{
Barri L. Schnall, MPT; ${ }^{1 *}$ Brad D. Hendershot, PhD; ${ }^{1-2}$ Johanna C. Bell, MSE; ${ }^{1}$ Erik J. Wolf, PhD ${ }^{1,3}$ \\ ${ }^{1}$ Department of Orthopaedics and Rehabilitation, Walter Reed National Military Medical Center, Bethesda, MD; \\ ${ }^{2}$ Department of Physical Medicine and Rehabilitation, Center for Rehabilitation Sciences Research, Uniformed Services \\ University of the Health Sciences, Bethesda, MD; ${ }^{3}$ Extremity Trauma and Amputation Center of Excellence, Military \\ Health System, Bethesda, MD
}

\begin{abstract}
The biomechanical responses to load carriage, a common task for dismounted troops, have been well studied in nondisabled individuals. However, with recent shifts in the rehabilitation and retention process of injured servicemembers, there remains a substantial need for understanding these responses in persons with lower-limb amputations. Temporalspatial and kinematic gait parameters were analyzed among 10 male servicemembers with unilateral transtibial amputation (TTA) and 10 uninjured male controls. Participants completed six treadmill walking trials in all combinations of two speeds $(1.34$ and $1.52 \mathrm{~m} / \mathrm{s}$ ) and three loads (none, 21.8 , and $32.7 \mathrm{~kg}$ ). Persons with TTA exhibited biomechanical compensations to carried loads that are comparable to those observed in uninjured individuals. However, several distinct gait changes appear to be unique to those with TTA, notably, increased dorsiflexion (deformation) of the prosthetic foot/ankle, less stance knee flexion on the prosthetic limb, and altered trunk forward lean/excursion. Such evidence supports the need for future work to assess the risk for overuse injuries with carried loads in this population in addition to guiding the development of adaptive prosthetic feet/components to meet the needs of redeployed servicemembers or veterans/civilians in physically demanding occupations.
\end{abstract}

Key words: amputation, biomechanics, gait, kinematics, load carriage, military, return to duty, transtibial, treadmill, unilateral.

\section{INTRODUCTION}

A progressive shift in the medical evaluation, rehabilitation, and retention of injured military personnel has provided considerable opportunity and prospect for servicemembers with lower-limb amputations to remain on Active Duty. More than 1,400 servicemembers have sustained injuries resulting in a major limb amputation during recent conflicts [1], and among those with a transtibial amputation (TTA), approximately 20 percent remain on Active Duty [2]. Yet despite investigations of the physiological and biomechanical responses to load carriage in nondisabled military and civilian populations [3-6], there remains limited objective evidence [7] regarding the ability of servicemembers with lower-limb amputations to meet military standards when executing physical tasks (e.g., load carriage).

\footnotetext{
Abbreviations: ANOVA $=$ analysis of variance, MOLLE $=$ modular lightweight load-carrying equipment, OTV $=$ outer tactical vest, $\mathrm{SD}=$ standard deviation, TTA = transtibial amputation.

*Address all correspondence to Barri L. Schnall, MPT; Walter Reed National Military Medical Center, America Building No. 19, Room B313, 8901 Wisconsin Ave, Bethesda, MD 20889; 301-400-2096. Email: barri.l.schnall.civ@mail.mil http://dx.doi.org/10.1682/JRRD.2014.01.0022
} 
In nondisabled individuals, loads carried on the body alter the temporal-spatial and kinematic parameters of gait. For example, decreased step length, increased double-limb support time, and reduced gait speed have all been observed with increasing loads carried on the body [8]. Increases in stance knee flexion [9-11], knee and hip range of motion [9,11], and forward lean of the trunk $[3,9,12]$ are also commonly observed with increasing load magnitude. Such alterations in temporal-spatial and kinematic gait parameters have been suggested to contribute to the stability of the body-plus-load system by increasing the duration of time the lower limbs spend in contact with the ground and/or by lowering the position of (or reducing movement in) the body-plus-load center of mass. Changes in lower-limb kinematics (e.g., stance knee flexion) compared with unloaded gait may also help reduce or absorb impact forces transmitted through the body during load carriage tasks $[3,10]$.

Altered and asymmetric gait among persons with lower-limb amputations, which are commonly observed during unloaded walking [13], may further degrade in response to load carriage. Intact limbs can respond to changes in external demands by altering the activity of muscles crossing the joint. For example, the ability of the lower-limb musculature to maintain similar ankle joint kinematics during load carriage in nondisabled individuals [8] suggests that substantial internal joint moments are generated to counter external loads. Most current prosthetic ankle/foot systems, however, are not capable of providing such variations in dynamic "stiffness" in response to changing external demands because they are prescribed according to the unloaded weight and activity level of the individual. A recent modeling study indicated that the stiffness of the prosthesis needs to be increased for carried loads exceeding 20 percent body weight [14]. This is of particular importance to military applications since reports on recent U.S. military operations reveal that light infantry troops are carrying loads up to $45 \mathrm{~kg}(100 \mathrm{lb})$ or more during dismounted operations [4]. Thus, increased loads carried on the body among servicemembers with TTA may induce substantial motion at the prosthetic ankle joint and/ or alter the kinematics of other joints throughout the body.

The primary objective of the current study was to quantify and compare temporal-spatial and kinematic gait parameters in servicemembers with and without unilateral TTA during several military-relevant loaded walking conditions. We hypothesized that the magnitudes of changes in temporal-spatial and kinematic gait parameters with increasing load mass and/or walking speed would be larger (and bilaterally asymmetric) among servicemembers with unilateral TTA than in uninjured controls.

\section{METHODS}

\section{Participants}

Ten males with unilateral TTA and ten uninjured male controls participated after completing informed consent procedures approved by the local institutional review board. All participants were active military servicemembers, between the ages of 18 and $35 \mathrm{yr}$, and capable of treadmill walking at multiple speeds while carrying loads. Additional inclusion criteria for participants with TTA included at least 6 mo of independent ambulation prior to participation. Potential participants in both groups were excluded if they had any history of medical conditions preventing cardiovascular training and/or comorbidities or pain that may affect independent ambulation. Participants with TTA were tested in their current socket and wore their preferred energy-storing and return feet, which included the VSP $(n=4)$ and Ceterus $(n=3)$ (Össur; Reykjavík, Iceland) and Renegade $(n=3$; Freedom Innovations LLC; Irvine, California). Mean \pm standard deviation (SD) age, stature, and body mass for the participants with TTA were $24.9 \pm 2.8 \mathrm{yr}, 183.3 \pm 6.3 \mathrm{~cm}$, and $94.1 \pm$ $18.5 \mathrm{~kg}$, respectively. Corresponding values for the 10 controls were $21.3 \pm 3.0 \mathrm{yr}, 181.7 \pm 5.4 \mathrm{~cm}$, and $88.9 \pm$ $8.1 \mathrm{~kg}$. Body mass measurements were obtained while the participants with unilateral TTA were wearing their prostheses. All amputations were the result of traumatic injuries, with a mean \pm SD time since amputation of $22.9 \pm$ 18.9 mo.

\section{Experimental Design and Procedures}

A repeated-measures design was used, in which participants walked in all combinations of two controlled speeds $(1.34$ and $1.52 \mathrm{~m} / \mathrm{s})$ and three loading conditions (none, 21.8, and $32.7 \mathrm{~kg}$ ). The two speed conditions were completed in separate sessions on two consecutive days; the three loading conditions were randomized within each session. These speeds and load magnitudes are consistent with published military guidance regarding the speed and load magnitudes to be carried during a foot march $[5,15]$ and are representative of values used in previous studies assessing load carriage by nondisabled servicemembers [16-17]. 
During each experimental condition, participants walked for $10 \mathrm{~min}$, without handrail support, on a medicalgrade treadmill (Woodway PPS 55; Waukesha, Wisconsin) set to the horizontal position. Participants were provided at least $20 \mathrm{~min}$ of rest between each condition to minimize the effects of fatigue, and the timing of these events was established by a previous protocol in which the metabolic cost of load carriage was assessed in these same participants [18]. For all conditions, participants wore a T-shirt, shorts, socks, and athletic shoes, as well as a helmet and mock weapon $(\sim 3 \mathrm{~kg})$ carried in both hands across the front of the body (i.e., the "ready" position). Note, the total mass of the clothing, helmet, and mock weapon is not reflected in the labeling of load conditions (i.e., none, 21.8 , and $32.7 \mathrm{~kg}$ ). The $21.8 \mathrm{~kg}$ load condition included an additional ballistic protective vest, and the $32.7 \mathrm{~kg}$ condition consisted of a modular lightweight load-carrying equipment (MOLLE) rucksack and outer tactical vest (OTV) (Figure 1). The MOLLE and OTV were loaded with items that soldiers typically carry: mock rounds of ammunition and mock grenades were placed in pockets and pouches attached to the front of the MOLLE, and a $1 \mathrm{qt}$, water-filled canteen was attached to the OTV at waist level.

Full-body kinematics were collected throughout three consecutive $10 \mathrm{~s}$ periods within each condition $(8 \mathrm{~min}$ into the walk) using retro-reflective markers placed on bony landmarks and according to a modified Cleveland Clinic marker set [19]. Marker positions were collected $(120 \mathrm{~Hz})$ using at least an 8-camera motion capture system (Motion Analysis Corporation; Santa Rosa, California, or Vicon; Oxford, United Kingdom). All raw marker data were lowpass filtered using a second-order, bidirectional, Butterworth filter with a $6 \mathrm{~Hz}$ cutoff frequency.

\section{Dependent Measures and Analyses}

Temporal-spatial and joint kinematic (flexionextension) parameters were calculated using an 8segment biomechanical model in Visual 3D (C-Motion Inc; Germantown, Maryland). All data were timenormalized to a stride (100\% gait cycle). Subsequently, peak joint angles were identified for each limb, including ankle dorsiflexion, ankle plantar flexion, stance knee flexion, hip flexion and extension (angle between thigh and trunk due to frequent obstruction of pelvic markers by the load-bearing equipment or weapon), and trunk forward lean angle (relative to vertical). Joint excursions were calculated as the difference between maximum and minimum joint angles throughout the normalized gait

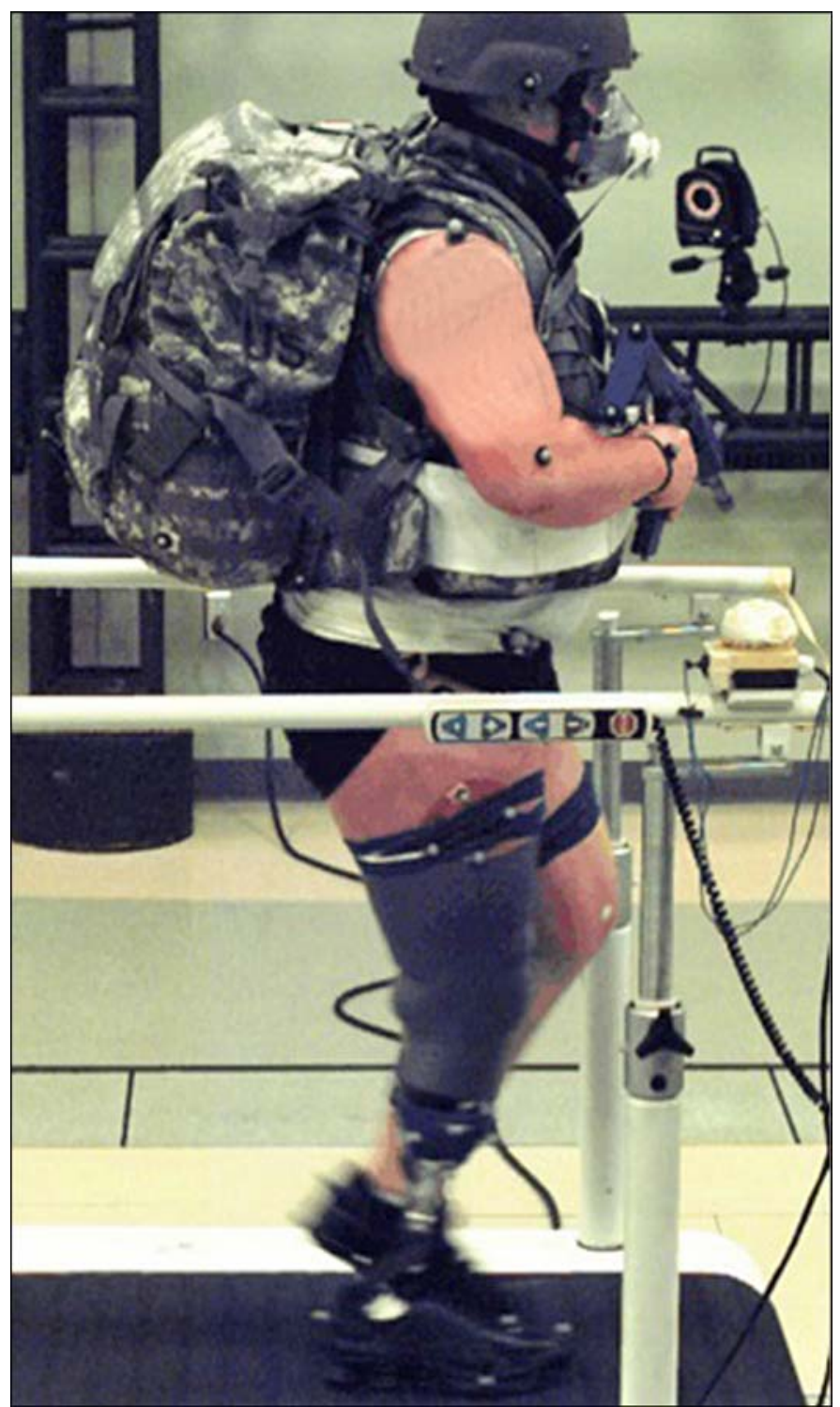

Figure 1.

Experimental setup demonstrating $32.7 \mathrm{~kg}$ loaded walking condition.

cycle. Temporal-spatial parameters were calculated, including stride time, step length and step width, doublelimb support, and stance phase durations (percent of gait cycle).

Initially, multivariate analyses of variance (ANOVAs) were used to assess temporal-spatial and kinematic parameters across all strides throughout the three $10 \mathrm{~s}$ collections in each experimental condition. Mean values were computed for each $10 \mathrm{~s}$ trial since no significant effects were found. Two sets of mixed-factor repeated-measures ANOVAs 
were then used to assess (1) the main and interactive effects of limb (group) and speed during the two unloaded conditions and (2) the main and interactive effects of load magnitude, gait speed, and limb (group) during the four loaded conditions. For the latter, difference scores were computed by subtracting the raw parameters in each no-load condition from the four loaded conditions (separately for each speed). Since initial analyses (also using mixed-factor ANOVAs) revealed no significant differences between right/left limbs among controls, the right limb was used to represent the uninjured control group/limb, while separate responses (prosthetic and intact) were analyzed among participants with unilateral TTA. Where relevant, post hoc comparisons were performed using Tukey honestly significant difference tests. All analyses were done using JMP (version 10, SAS Institute Inc; Cary, North Carolina), and statistical significance was concluded when $p<0.05$. Summary values are reported as mean $\pm \mathrm{SD}$. Data from two participants with TTA during the $32.7 \mathrm{~kg}$ loading condition (one at $1.34 \mathrm{~m} / \mathrm{s}$ and both at $1.52 \mathrm{~m} / \mathrm{s}$ ) were excluded from these analyses because of measurement error and/or participant dropout.

\section{RESULTS}

\section{Temporal-Spatial Parameters}

In the unloaded conditions, stride times were shorter $(p<0.001)$ while step widths and double limb support durations were wider $(p<0.001)$ and longer $(p=0.004)$, respectively, among participants with TTA compared with controls (Table 1). Stance durations were also longer ( $p=$ 0.003 ) on the intact limb versus prosthetic/control limbs (Table 1).

Stride times decreased with increasing load $(p<$ $0.001)$ and at faster walking speeds $(p<0.001)$. These decreases were also significantly larger $(p=0.04)$ with added load among participants with TTA than among uninjured controls. Step widths increased $(p=0.02)$ with increasing load and were larger $(p=0.03)$ among participants with TTA versus uninjured controls (Table 2) but were similar between speeds $(p=0.44)$. In both groups, double-limb support durations increased $(p<0.001)$ with increasing load, though these increases were larger $(p=$ $0.01)$ at 1.34 versus $1.52 \mathrm{~m} / \mathrm{s}$ among participants with

Table 1.

Mean \pm standard deviation temporal-spatial and joint kinematic parameters during no-load conditions by group/limb at both speeds. Measures with only one value per group are listed under intact limb for participants with transtibial amputation.

\begin{tabular}{|c|c|c|c|c|c|c|}
\hline \multirow{2}{*}{ Parameter } & \multicolumn{3}{|c|}{ Speed $=1.34 \mathrm{~m} / \mathrm{s}$} & \multicolumn{3}{|c|}{ Speed = $1.52 \mathrm{~m} / \mathrm{s}$} \\
\hline & Control & Intact & Prosthetic & Control & Intact & Prosthetic \\
\hline \multicolumn{7}{|l|}{ Temporal-Spatial } \\
\hline Step Width $(\mathrm{cm})^{\dagger}$ & $10.7 \pm 2.1^{\mathrm{a}}$ & $15.2 \pm 3.0^{\mathrm{b}}$ & - & $10.8 \pm 1.6^{\mathrm{a}}$ & $15.0 \pm 3.3^{\mathrm{b}}$ & - \\
\hline Double Limb Support $(\%)^{\dagger \dagger}$ & $26.8 \pm 2.2^{\mathrm{a}}$ & $30.5 \pm 2.0^{\mathrm{c}}$ & - & $25.6 \pm 1.3^{\mathrm{b}}$ & $30.8 \pm 3.7^{\mathrm{c}}$ & - \\
\hline \multicolumn{7}{|l|}{ Peak Joint Angles $\left({ }^{\circ}\right)$} \\
\hline Ankle Dorsiflexion ${ }^{*}$ & $18.6 \pm 2.2^{\mathrm{a}}$ & $18.7 \pm 4.3^{\mathrm{a}}$ & $21.7 \pm 3.8^{\mathrm{a}}$ & $17.8 \pm 3.1^{\mathrm{a}}$ & $18.3 \pm 2.2^{\mathrm{a}}$ & $19.4 \pm 3.5^{\mathrm{a}}$ \\
\hline Ankle Plantar Flexion ${ }^{* \dagger}$ & $-12.8 \pm 4.1^{\mathrm{a}}$ & $-10.3 \pm 5.2^{\mathrm{a}}$ & $-0.4 \pm 2.6^{\mathrm{b}}$ & $-14.4 \pm 5.3^{\mathrm{a}}$ & $-11.4 \pm 5.6^{\mathrm{a}}$ & $-3.6 \pm 2.8^{\mathrm{b}}$ \\
\hline Stance Knee Flexion ${ }^{*}$ & $22.8 \pm 5.5^{\mathrm{a}}$ & $21.3 \pm 6.2^{\mathrm{a}}$ & $19.6 \pm 9.4^{\mathrm{a}}$ & $24.9 \pm 5.2^{\mathrm{a}}$ & $23.9 \pm 5.4^{\mathrm{a}}$ & $16.0 \pm 10.2^{\mathrm{a}}$ \\
\hline Hip Flexion & $19.0 \pm 3.9^{\mathrm{a}}$ & $19.8 \pm 5.4^{\mathrm{a}}$ & $22.1 \pm 4.8^{\mathrm{a}}$ & $20.0 \pm 3.3^{\mathrm{a}}$ & $20.8 \pm 3.3^{\mathrm{a}}$ & $21.2 \pm 7.6^{\mathrm{a}}$ \\
\hline Ankle & $31.8 \pm 4.1^{\mathrm{a}}$ & $29.0 \pm 5.6^{\mathrm{a}}$ & $22.1 \pm 3.7^{\mathrm{b}}$ & $32.2 \pm 4.2^{\mathrm{a}}$ & $29.7 \pm 5.5^{\mathrm{a}}$ & $23.0 \pm 2.9^{b}$ \\
\hline Knee & $72.0 \pm 3.9^{\mathrm{a}}$ & $67.8 \pm 6.8^{\mathrm{a}}$ & $69.7 \pm 4.7^{\mathrm{a}}$ & $70.4 \pm 3.8^{\mathrm{a}}$ & $65.7 \pm 6.7^{\mathrm{a}}$ & $72.1 \pm 5.5^{\mathrm{a}}$ \\
\hline $\operatorname{Hip}^{* \dagger}$ & $46.4 \pm 3.8^{\mathrm{a}}$ & $44.4 \pm 3.3^{\mathrm{a}}$ & $40.6 \pm 2.9^{b}$ & $47.7 \pm 4.3$ & $46.6 \pm 4.5$ & $43.3 \pm 3.4$ \\
\hline Trunk $\dagger$ & $3.8 \pm 1.1^{\mathrm{a}}$ & $2.6 \pm 3.6^{\mathrm{b}}$ & - & $4.1 \pm 1.2^{\mathrm{a}}$ & $2.9 \pm 3.5^{\mathrm{ab}}$ & - \\
\hline
\end{tabular}

Note: Significant effects of speed $(*)$, limb/group $(\dagger)$, and limb/group $\times$ speed interactions $(\ddagger)$ are indicated to right of each measure. Results from post hoc pairwise comparisons (within each measure) are indicated by letters to right of each value, where values that share the same letter are not significantly different from each other. 
Table 2.

Mean \pm standard deviation relative change (to unloaded conditions at each speed) in temporal-spatial and sagittal joint kinematic parameters by group/limb (control, intact, and prosthetic) and load condition (21.8 and $32.7 \mathrm{~kg}$ ). Measures with only one value per group are listed under intact limb for participants with transtibial amputation.

\begin{tabular}{|c|c|c|c|c|c|c|c|c|c|c|c|c|}
\hline \multirow{3}{*}{ Parameter } & \multicolumn{6}{|c|}{ Speed $=1.34 \mathrm{~m} / \mathrm{s}$} & \multicolumn{6}{|c|}{ Speed $=1.52 \mathrm{~m} / \mathrm{s}$} \\
\hline & \multicolumn{2}{|c|}{ Control } & \multicolumn{2}{|c|}{ Intact } & \multicolumn{2}{|c|}{ Prosthetic } & \multicolumn{2}{|c|}{ Control } & \multicolumn{2}{|c|}{ Intact } & \multicolumn{2}{|c|}{ Prosthetic } \\
\hline & $21.8 \mathrm{~kg}$ & $32.7 \mathrm{~kg}$ & $21.8 \mathrm{~kg}$ & 32.7 kg & $21.8 \mathrm{~kg}$ & 32.7 kg & $21.8 \mathrm{~kg}$ & 32.7 kg & $21.8 \mathrm{~kg}$ & 32.7 kg & $21.8 \mathrm{~kg}$ & $32.7 \mathrm{~kg}$ \\
\hline \multicolumn{13}{|l|}{ Temporal-Spatial } \\
\hline Stride Time $(\mathrm{s})^{* \dagger}$ & $-0.1 \pm 0.1$ & $0.0 \pm 0.1$ & $-0.2 \pm 0.3$ & $-0.1 \pm 0.2$ & - & - & $-0.1 \pm 0.1$ & $-0.1 \pm 0.1$ & $-0.3 \pm 0.2$ & $-0.2 \pm 0.2$ & - & - \\
\hline Step Width $(\mathrm{cm})^{\dagger}$ & $0.2 \pm 1.9$ & $0.1 \pm 1.6$ & $0.6 \pm 0.9$ & $1.0 \pm 1.8$ & - & - & $0.6 \pm 0.4$ & $1.1 \pm 0.5$ & $0.6 \pm 1.5$ & $0.3 \pm 1.6$ & - & - \\
\hline $\begin{array}{l}\text { Double Limb } \\
\text { Support }(\%)^{* \dagger}\end{array}$ & $1.2 \pm 0.7$ & $2.4 \pm 1.0$ & $3.3 \pm 1.4$ & $3.9 \pm 1.5$ & - & - & $1.7 \pm 0.8$ & $3.2 \pm 0.7$ & $1.0 \pm 2.6$ & $2.6 \pm 3.1$ & - & - \\
\hline Step Length $(\mathrm{cm})^{\dagger}$ & $0.1 \pm 1.4$ & $-0.9 \pm 1.3$ & $-2.1 \pm 3.2$ & $-1.7 \pm 2.6$ & $-1.9 \pm 2.7$ & $0.9 \pm 1.9$ & $-0.1 \pm 1.7$ & $-1.5 \pm 1.2$ & $-1.6 \pm 2.5$ & $-1.0 \pm 1.3$ & $-1.7 \pm 2.6$ & $0.7 \pm 2.2$ \\
\hline $\begin{array}{l}\text { Stance Duration } \\
(\%)^{* \dagger \dagger}\end{array}$ & $0.5 \pm 0.6$ & $1.3 \pm 0.6$ & $2.2 \pm 1.7$ & $3.2 \pm 1.3$ & $1.6 \pm 0.7$ & $0.8 \pm 1.7$ & $0.8 \pm 0.6$ & $1.7 \pm 0.6$ & $0.4 \pm 1.5$ & $1.5 \pm 2.2$ & $0.6 \pm 1.2$ & $1.3 \pm 1.4$ \\
\hline \multicolumn{13}{|l|}{ Peak Joint Angles $\left({ }^{\circ}\right)$} \\
\hline Ankle Dorsiflexion* & $1.3 \pm 1.2$ & $0.6 \pm 1.8$ & $0.5 \pm 1.6$ & $-0.5 \pm 1.8$ & $0.9 \pm 0.9$ & $2.3 \pm 1.1$ & $1.1 \pm 1.2$ & $0.5 \pm 1.8$ & $0.5 \pm 1.3$ & $-0.2 \pm 1.7$ & $1.7 \pm 1.2$ & $2.8 \pm 1.7$ \\
\hline $\begin{array}{l}\text { Ankle Plantar } \\
\text { Flexion }\end{array}$ & $0.3 \pm 1.1$ & $0.3 \pm 2.0$ & $-0.1 \pm 2.2$ & $-0.5 \pm 2.4$ & $0.2 \pm 1.3$ & $-0.3 \pm 1.1$ & $0.5 \pm 1.8$ & $-0.3 \pm 1.4$ & $0.5 \pm 1.3$ & $-0.3 \pm 2.5$ & $0.7 \pm 1.6$ & $0.3 \pm 1.6$ \\
\hline Stance Knee Flexion & $0.7 \pm 1.7$ & $1.6 \pm 2.4$ & $0.9 \pm 1.2$ & $2.3 \pm 1.6$ & $0.7 \pm 2.8$ & $1.2 \pm 2.4$ & $0.3 \pm 2.9$ & $1.4 \pm 2.2$ & $2.3 \pm 2.1$ & $1.8 \pm 2.9$ & $2.0 \pm 3.3$ & $1.8 \pm 4.3$ \\
\hline Hip Flexion ${ }^{* \dagger}$ & $-1.0 \pm 1.7$ & $5.9 \pm 1.6$ & $-3.0 \pm 3.2$ & $4.7 \pm 4.1$ & $-2.6 \pm 3.9$ & $4.3 \pm 2.4$ & $-1.4 \pm 2.5$ & $7.2 \pm 4.0$ & $-1.2 \pm 3.9$ & $4.8 \pm 5.7$ & $-0.8 \pm 4.3$ & $5.8 \pm 5.0$ \\
\hline Hip Extension ${ }^{\dagger \dagger}$ & $-2.1 \pm 1.6$ & $1.9 \pm 1.7$ & $-5.5 \pm 2.9$ & $-1.5 \pm 2.8$ & $-5.0 \pm 4.7$ & $0.3 \pm 3.9$ & $-2.0 \pm 3.1$ & $3.3 \pm 3.9$ & $-4.1 \pm 4.5$ & $-1.6 \pm 5.2$ & $-4.1 \pm 5.0$ & $-0.1 \pm 6.5$ \\
\hline Trunk Forward Lean ${ }^{\dagger}$ & $2.3 \pm 1.2$ & $4.5 \pm 0.9$ & $4.0 \pm 2.7$ & $-2.8 \pm 2.9$ & - & - & $2.1 \pm 1.5$ & $4.4 \pm 1.4$ & $2.1 \pm 2.8$ & $-2.5 \pm 3.4$ & - & - \\
\hline \multicolumn{13}{|l|}{ Joint Excursions $\left({ }^{\circ}\right)$} \\
\hline Ankle* & $0.9 \pm 1.3$ & $0.4 \pm 1.5$ & $0.5 \pm 1.5$ & $-0.1 \pm 2.3$ & $0.8 \pm 1.2$ & $2.7 \pm 1.1$ & $0.7 \pm 1.1$ & $0.8 \pm 0.9$ & $0.7 \pm 2.0$ & $0.1 \pm 2.2$ & $1.0 \pm 1.2$ & $2.4 \pm 0.9$ \\
\hline $\mathrm{Knee}^{\dagger+}$ & $-1.3 \pm 1.8$ & $-2.7 \pm 1.1$ & $-0.3 \pm 2.8$ & $-0.7 \pm 2.2$ & $-1.2 \pm 3.8$ & $-1.9 \pm 3.8$ & $-2.4 \pm 1.5$ & $-3.3 \pm 1.9$ & $0.1 \pm 1.5$ & $0.4 \pm 2.7$ & $0.3 \pm 2.1$ & $-0.9 \pm 3.1$ \\
\hline $\mathrm{Hip}^{\dagger+}$ & $1.1 \pm 0.7$ & $3.9 \pm 1.4$ & $2.4 \pm 1.9$ & $6.2 \pm 2.9$ & $2.5 \pm 2.7$ & $4.0 \pm 2.2$ & $0.6 \pm 1.5$ & $3.8 \pm 1.4$ & $3.0 \pm 2.4$ & $6.5 \pm 2.8$ & $3.3 \pm 2.3$ & $5.9 \pm 2.7$ \\
\hline Trunk & $-0.5 \pm 0.6$ & $0.1 \pm 0.8$ & $0.5 \pm 1.8$ & $0.1 \pm 0.9$ & - & - & $-0.6 \pm 1.1$ & $0.8 \pm 3.1$ & $0.1 \pm 0.6$ & $0.6 \pm 0.6$ & - & - \\
\hline
\end{tabular}

Note: Significant main effects of speed $\left(^{*}\right)$, load $(\dagger)$, and limb/group ( $\left.{ }^{\star}\right)$, are indicated to right of each measure, and significant limb/group $\times$ load comparisons (within each measure) are indicated by shaded cells.

TTA. Step lengths decreased $(p=0.004)$ with added load among controls and on the intact limb among participants with TTA. On the prosthetic limb, however, step lengths decreased with the $21.8 \mathrm{~kg}$ load but not with $32.7 \mathrm{~kg}$ (Table 2). Stance durations increased $(p=0.002)$ with increasing load, with larger $(p=0.003)$ increases at 1.34 versus $1.52 \mathrm{~m} / \mathrm{s}$. Stance durations were also significantly $(p<0.001)$ longer in the intact versus prosthetic/control limbs (Table 2).

\section{Peak Joint Angles}

In the unloaded conditions, peak ankle plantar flexion was significantly $(p<0.001)$ smaller on the prosthetic versus intact/control limbs (Figure 2, Table 1). Peak trunk forward lean angles were greater $(p<0.001)$ in participants with TTA than controls (Figure 2, Table 1).

Peak ankle dorsiflexion remained similar $(p=0.69)$ with added load among controls and on the intact limb among participants with TTA, but increased $(p<0.001)$ with added load on the prosthetic limb (Table 2); these did not differ $(p=0.32)$ by walking speed. Peak ankle plantar flexion was similar $(p=0.17)$ with added load and between walking speeds $(p=0.62)$ and limbs $(p=0.67)$. Changes in peak stance knee flexion were also similar between loads $(p=0.20)$, walking speeds $(p=0.37)$, and limbs $(p=0.37)$. Peak hip flexion increased $(p<0.001)$ with increasing load; these increases were larger $(p=0.03)$ at 1.52 versus $1.34 \mathrm{~m} / \mathrm{s}$ but were similar $(p=0.64)$ between limbs. Peak hip extension decreased $(p<0.001)$ with added load; this decrease was larger during the 21.8 versus $32.7 \mathrm{~kg}$ loading condition. Peak hip extension also decreased $(p<$ $0.001)$ more on the prosthetic/intact versus control limbs. Peak trunk forward lean increased $(p<0.001)$ with increasing load among controls. Among participants with TTA, however, peak trunk forward lean increased in the $21.8 \mathrm{~kg}$ condition but decreased with $32.7 \mathrm{~kg}$. Changes in peak trunk forward lean were similar $(p=0.44)$ between walking speeds. 
(a)



(b)

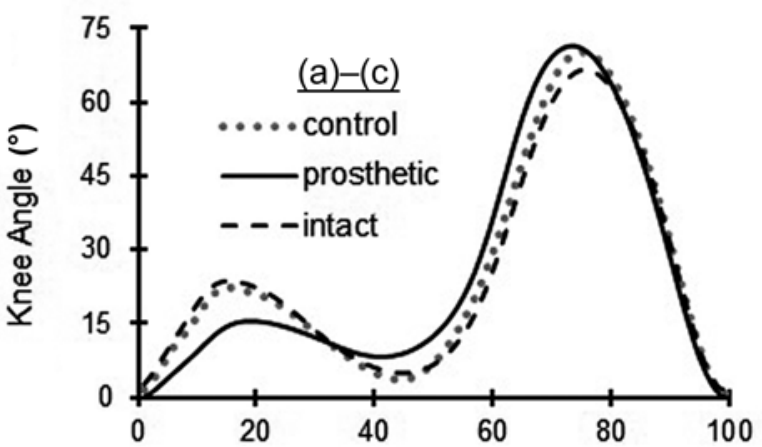

(c)

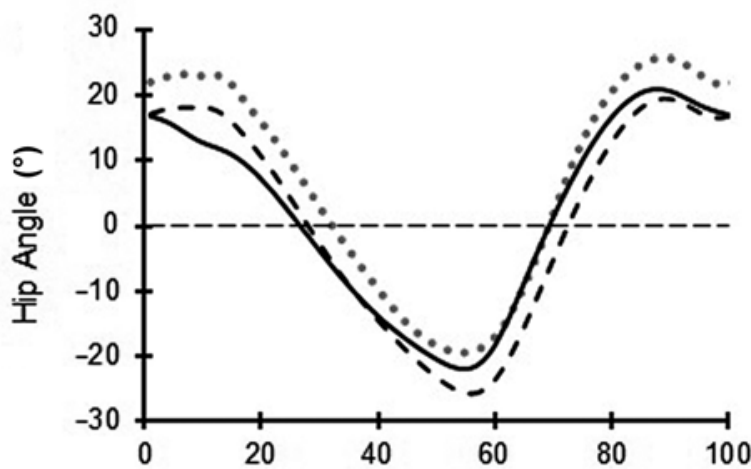

(d)

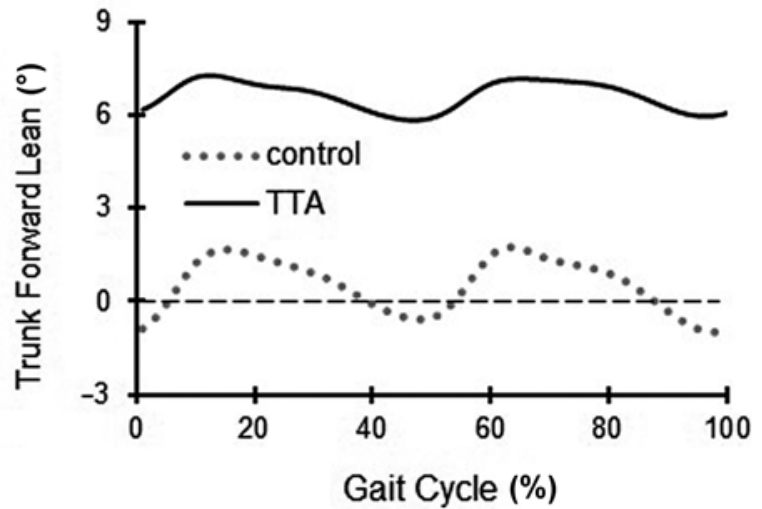

$\operatorname{LOAD}(32.7 \mathrm{~kg})$
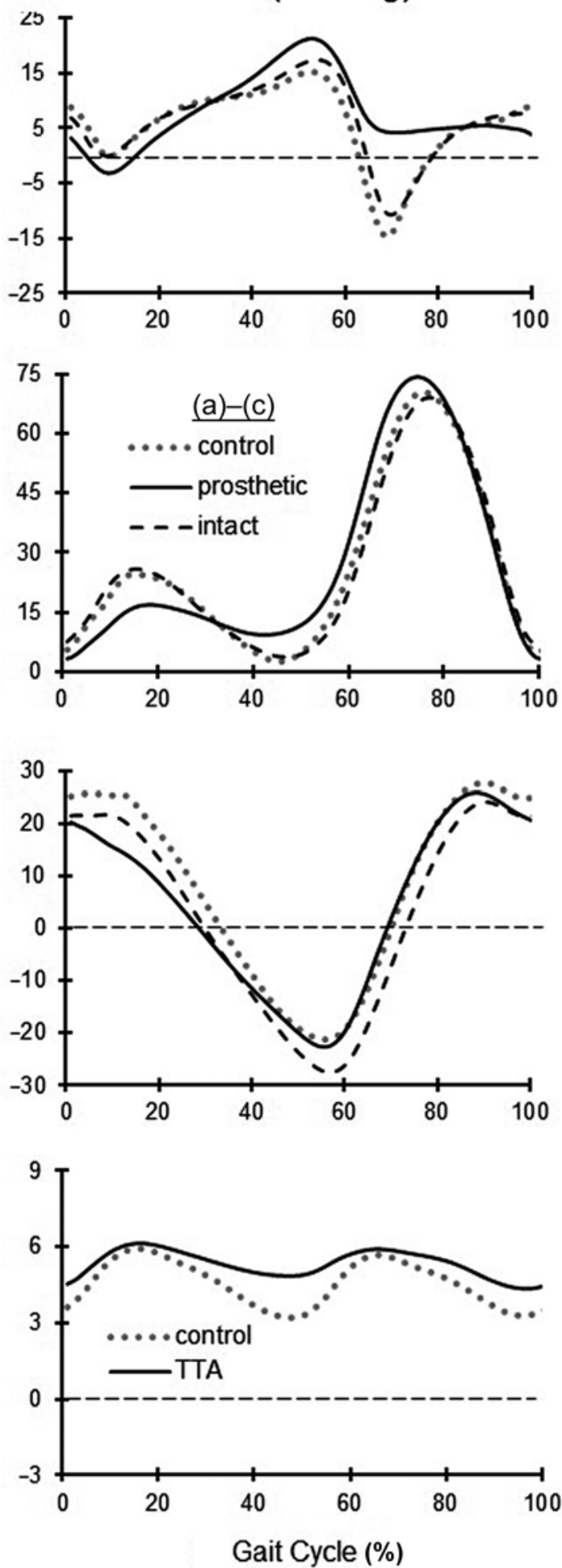

Figure 2.

Joint kinematics for no load (left) and $32.7 \mathrm{~kg}$ (right) conditions, both at $1.52 \mathrm{~m} / \mathrm{s}$ walking speed (positive angles = flexion). Curves represent ensemble averages for each limb (group), time-normalized to percentage gait cycle. (a) Ankle angle, (b) knee angle, (c) hip angle, and (d) trunk forward lean. TTA = transtibial amputation. 


\section{Joint Excursions}

In the unloaded conditions, joint excursions in the prosthetic limb were smaller at the ankle and hip at both speeds (Table 1).

During loaded conditions, increases in ankle excursions were larger $(p=0.01)$ in the prosthetic than intact/ control limbs but were similar between loads $(p=0.19)$ and walking speeds ( $p=0.62$; Table 2). Knee excursions decreased $(p=0.047)$ with increasing load; these decreases were larger $(p=0.02)$ among control versus prosthetic/ intact limbs (Table 2). Hip excursions increased $(p<$ 0.001 ) with increasing load, and these increases were larger $(p=0.01)$ on the prosthetic/intact than the control limbs. Trunk excursions were similar between groups $(p=$ $0.34)$ and loads $(p=0.11)$ (Table 2).

\section{DISCUSSION}

This study assessed temporal-spatial and joint kinematic parameters during military-relevant loaded walking in servicemembers with and without TTA. We hypothesized that the magnitude of changes in temporal-spatial and kinematic gait parameters with increasing load mass and/or walking speed would be larger (and more asymmetric) among servicemembers with TTA than uninjured controls. With carried load, several significant and notable differences were observed from those common to loaded walking in nondisabled individuals and which were generally in support of our hypothesis. Also of note, group and limb comparisons during the two unloaded conditions were consistent with existing research (for a review, see Sagawa et al. [13]).

Alterations in temporal-spatial gait parameters with carried load were consistent with the literature on weighted walking in nondisabled individuals and are commonly interpreted as mechanisms to improve postural stability and reduce the magnitude of forces transmitted through the body [3,6,9-10]. Among participants with TTA during the loaded walking conditions, increases in step width and the percentage of double limb support were larger than uninjured controls, especially at the slower $(1.34 \mathrm{~m} / \mathrm{s})$ walking speed. With increasing load magnitude, participants with TTA also took significantly shorter steps and increased stance durations with/on the intact limb. At the faster $(1.54 \mathrm{~m} / \mathrm{s})$ walking speed, however, changes in temporalspatial gait parameters were more similar between participants with and without TTA, with the exception of prosthetic side step length.
The most notable changes in lower-limb joint kinematics with carried load include increased knee and hip range of motion and stance knee flexion [8,11]. Again, similar and consistent results were observed among nondisabled controls in the present study. Most studies report no or inconsistent increases in ankle joint motion with added load [8-9]. Not surprisingly, however, the prosthetic ankle responded to added load with increased dorsiflexion in late stance as the body and load center of mass are shifted forward over the prosthetic keel. As noted earlier, prosthetic feet are prescribed according to the unloaded weight and activity level of the individual, and such increases in prosthetic ankle/foot dorsiflexion are likely a result of larger keel deformations. The lack of prosthetic ankle plantar flexion, common to both loaded and unloaded walking with a passive prosthetic foot, also reduces forward propulsion of the body; however, increases in prosthetic ankle dorsiflexion with carried load generates additional stored energy for push-off in late stance [7]. Greater stance knee flexion with added load has also been suggested to help improve stability of the body and load system, as well as reduce and/or absorb impact forces $[3,10]$. Such an effect was observed among controls and the intact limb among participants with TTA, but the knee on the prosthetic side remained more extended throughout stance (Figure 2(b)). Increases in hip excursions with added load were larger on both the intact and prosthetic limbs among participants with TTA than in controls, supporting a theory that compensations at more proximal joints occur with added load. These increases in hip excursions among participants with TTA are a result of more hip flexion in early stance [7], which was maintained through stance, evidenced by small decreases in hip extension in late stance.

Increases in trunk forward lean with added load are another notable kinematic alteration [9]. Although a more upright posture is typically considered more efficient [10], forward trunk lean with posteriorly carried loads is often suggested as a mechanism to maintain the body and load center of mass within the base of support [3]. Here, similar increasing trends in peak trunk forward lean with added load were observed among controls (Figure 1). Among participants with TTA, however, trunk forward lean maximally increased in the $21.8 \mathrm{~kg}$ condition but decreased in the $32.7 \mathrm{~kg}$ condition. Such a finding may be due to the inability to produce an active prosthetic ankle plantar flexor torque that would be needed to resist collapse of the ankle as weight is transferred forward. 
Also, individuals with TTA tend to walk with more trunk forward lean during unloaded walking (Figure 2(d)) to assist with forward propulsion of the body, which may further limit the extent to which these individuals can alter trunk posture with added load. Smaller (albeit not significant) trunk flexion-extension excursions among participants with TTA are consistent with recent evidence, which were suggested to reduce the inertial effects of the upper body and help control the added mass [7].

\section{LIMITATIONS}

The current results are likely not generalizable to older and less active individuals or those with more proximal (i.e., transfemoral) amputations. Controlling prosthetic foot type could also provide additional information for characterizing the prosthetic foot response to added loads. Despite the use of redundant markers to track the pelvis, considerable marker dropout resulted in a lack of accurate and consistent pelvis data. Such data could provide additional information for assessing injury risk, particularly related to the lower back [20-21]. Also, participants in the current study wore athletic sneakers as opposed to combat boots that would be commonly worn in theater. While there exists some research comparing the effects of (military) footwear on gait biomechanics [22-23], additional work is needed in populations with lower-limb amputations, both with and without load. It would also be of interest in the future to collect similar temporal-spatial and kinematic outcomes during sloped (incline and decline) weighted walking, as well as for sustained durations $[17,24]$. Because our treadmill was not instrumented to collect ground reaction force data, future work should also collect kinetics in order to investigate potential differences in limb loading with added load among persons with lower-limb amputations [7,25]. Lastly, although our analyses utilized a within-subject change score relative to unloaded walking, some caution is warranted when interpreting gait outcomes obtained on a treadmill versus overground, particularly among individuals with lower-limb amputations [26].

\section{CONCLUSIONS}

In summary, load carriage among persons with unilateral TTA results in some biomechanical changes that are consistent with those observed among nondisabled individuals. Despite these similarities, additional biomechanical compensations occur that appear to be unique to those with TTA, notably, increased dorsiflexion (deformation) of the prosthetic foot/ankle, less stance knee flexion on the prosthetic limb, and altered trunk forward lean/excursion. Such evidence supports the need for future work assessing the risk for overuse injuries with carried loads [7], as well as for guiding the development of multifunctional, highly adaptive, and responsive prosthetic feet/components for injured servicemembers who have redeployed or veterans/civilians with lower-limb amputations in physically demanding occupations.

\section{ACKNOWLEDGMENTS}

\section{Author Contributions:}

Study concept and design: B. L. Schnall.

Acquisition of data: B. L. Schnall, J. C. Bell, E. J. Wolf.

Analysis and interpretation of data: B. D. Hendershot, J. C. Bell. Drafting of manuscript: B. L. Schnall, B. D. Hendershot, J. C. Bell, E. J. Wolf.

Critical revision of manuscript and final approval: B. L. Schnall, B. D. Hendershot, J. C. Bell, E. J. Wolf.

Financial Disclosures: The authors have declared that no competing interests exist.

Funding/Support: This material was based on work supported by the Military Amputee Internal Research Program (grant USAMRMC W81XWH-06-2-0073) and the Center for Rehabilitation Sciences Research at the Uniformed Services University of Health Sciences (Defense Health Program NF90UG).

Additional Contributions: The authors would like to thank the staff at the Natick Soldier Center for their contributions to this project. Institutional Review: This study was approved by the local institutional review board and conducted in accordance with Federal Policy for the Protection of Human Subjects, United States, Department of Defense, 32 CFR Part 219. All participants provided informed consent. Participant Follow-Up: The authors do not plan to inform study participants of the publication of this study unless specifically requested. Disclaimer: The views expressed in this article are those of the authors and do not necessarily reflect the official policy or position of the Departments of the Army, Navy, Defense or the U.S. Government.

\section{REFERENCES}

1. Fischer HU. Military casualty statistics: Operation New Dawn, Operation Iraqi Freedom, and Operation Enduring Freedom. Washington (DC): Congressional Research Service; 2013. p. 1-13.

2. Walter Reed Amputee Database. Washington (DC): Department of the U.S. Army; 2013. 
3. Harman E, Hoon K, Frykman P, Pandorf C. The effects of backpack weight on the biomechanics of load carriage. Natick (MA): Military Performance Division, U.S. Army Research Institute of Environmental Medicine; 2000.

4. Knapik JJ, Reynolds KL, Harman E. Soldier load carriage: Historical, physiological, biomechanical, and medical aspects. Mil Med. 2004;169(1):45-56. [PMID:14964502]

5. Polcyn AF, Bensel CK, Harman EA, Obusek JP, Pandorf C, Frykman P. Effects of weight carried by soldiers: Combined analysis of four studies on maximal performance, physiology, and biomechanics. Natick (MA): U.S. Army Research Institute of Environmental Medicine; 2002.

6. Quesada PM, Mengelkoch LJ, Hale RC, Simon SR. Biomechanical and metabolic effects of varying backpack loading on simulated marching. Ergonomics. 2000;43(3): 293-309. [PMID:10755654]

http://dx.doi.org/10.1080/001401300184413

7. Doyle SS, Lemaire ED, Besemann M, Dudek NL. Changes to level ground transtibial amputee gait with a weighted backpack. Clin Biomech (Bristol, Avon). 2014;29(2):149-54. [PMID:24355702] http://dx.doi.org/10.1016/j.clinbiomech.2013.11.019

8. Birrell SA, Haslam RA. The effect of military load carriage on 3-D lower limb kinematics and spatiotemporal parameters. Ergonomics. 2009;52(10):1298-1304.

[PMID:19787507] http://dx.doi.org/10.1080/00140130903003115

9. Attwells RL, Birrell SA, Hooper RH, Mansfield NJ. Influence of carrying heavy loads on soldiers' posture, movements and gait. Ergonomics. 2006;49(14):1527-37.

[PMID:17050392] http://dx.doi.org/10.1080/00140130600757237

10. Kinoshita H. Effects of different loads and carrying systems on selected biomechanical parameters describing walking gait. Ergonomics. 1985;28(9):1347-62.

[PMID:4065090] http://dx.doi.org/10.1080/00140138508963251

11. Majumdar D, Pal MS, Majumdar D. Effects of military load carriage on kinematics of gait. Ergonomics. 2010; 53(6):782-91. [PMID:20496244] http://dx.doi.org/10.1080/00140131003672015

12. Goh JH, Thambyah A, Bose K. Effects of varying backpack loads on peak forces in the lumbosacral spine during walking. Clin Biomech (Bristol, Avon). 1998;13(1 Suppl 1):S26-31. [PMID:11430787] http://dx.doi.org/10.1016/S0268-0033(97)00071-5

13. Sagawa Y Jr, Turcot K, Armand S, Thevenon A, Vuillerme $\mathrm{N}$, Watelain E. Biomechanics and physiological parameters during gait in lower-limb amputees: A systematic review. Gait Posture. 2011;33(4):511-26. [PMID:21392998] http://dx.doi.org/10.1016/j.gaitpost.2011.02.003
14. Hitt J, Sugar T. Load carriage effects on a robotic transtibial prosthesis. Proceedings of the 2010 International Conference on Control Automation and Systems (ICCAS); 2010 Oct 27-30; Gyeonggi-do, Korea.

15. Foot marches. Washington (DC): Department of the U.S. Army; 1990.

16. Knapik J, Harman E, Reynolds K. Load carriage using packs: A review of physiological, biomechanical and medical aspects. Appl Ergon. 1996;27(3):207-16.

[PMID:15677062]

http://dx.doi.org/10.1016/0003-6870(96)00013-0

17. Patton JF, Kaszuba J, Mello RP, Reynolds KL. Physiological responses to prolonged treadmill walking with external loads. Eur J Appl Physiol Occup Physiol. 1991;63(2):89-93. [PMID:1748110] http://dx.doi.org/10.1007/BF00235175

18. Schnall BL, Wolf EJ, Bell JC, Gambel J, Bensel CK. Metabolic analysis of male servicemembers with transtibial amputations carrying military loads. J Rehabil Res Dev. 2012;49(4):535-44. [PMID:22773257] http://dx.doi.org/10.1682/JRRD.2011.04.0075

19. Collins TD, Ghoussayni SN, Ewins DJ, Kent JA. A six degrees-of-freedom marker set for gait analysis: Repeatability and comparison with a modified Helen Hayes set. Gait Posture. 2009;30(2):173-80. [PMID:19473844] http://dx.doi.org/10.1016/j.gaitpost.2009.04.004

20. LaFiandra M, Holt KG, Wagenaar RC, Obusek JP. Transverse plane kinetics during treadmill walking with and without a load. Clin Biomech (Bristol, Avon). 2002;17(2): 116-22. [PMID:11832261] http://dx.doi.org/10.1016/S0268-0033(01)00113-9

21. Smith B, Ashton KM, Bohl D, Clark RC, Metheny JB, Klassen S. Influence of carrying a backpack on pelvic tilt, rotation, and obliquity in female college students. Gait Posture. 2006;23(3):263-67. [PMID:16023856] http://dx.doi.org/10.1016/j.gaitpost.2005.02.009

22. Cikajlo I, Matjacić Z. The influence of boot stiffness on gait kinematics and kinetics during stance phase. Ergonomics. 2007;50(12):2171-82. [PMID:17886013] http://dx.doi.org/10.1080/00140130701582104

23. deMoya RG. A biomechanical comparison of the running shoe and the combat boot. Mil Med. 1982;147(5):380-83. [PMID:6810212]

24. Qu X, Yeo JC. Effects of load carriage and fatigue on gait characteristics. J Biomech. 2011;44(7):1259-63. [PMID:21397234] http://dx.doi.org/10.1016/j.jbiomech.2011.02.016

25. Birrell SA, Hooper RH, Haslam RA. The effect of military load carriage on ground reaction forces. Gait Posture. 2007;26(4):611-14. [PMID:17337189] http://dx.doi.org/10.1016/j.gaitpost.2006.12.008 
26. Button C, Moyle S, Davids K. Comparison of below-knee amputee gait performed overground and on a motorized treadmill. Adapt Phys Activ Q. 2010;27(2):96-112. [PMID:20440022]

Submitted for publication January 27, 2014. Accepted in revised form September 18, 2014.
This article and any supplementary material should be cited as follows:

Schnall BL, Hendershot BD, Bell JC, Wolf EJ. Kinematic analysis of males with transtibial amputation carrying military loads. J Rehabil Res Dev. 2014;51(10):1505-14. http://dx.doi.org/10.1682/JRRD.2014.01.0022

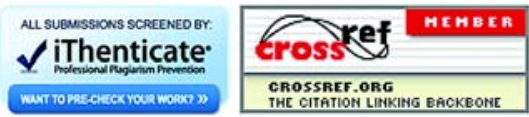

